\title{
Study of maternal serum lipid profile and apolipoprotein a levels and its correlation with fetal growth restriction
}

\author{
Akoijam Tamphasana Devi', Reena Yadav*, Amita Yadav, Yanglem Ajitkumar Singh'
}

\begin{abstract}
${ }^{1}$ Department of Obstetrics and Gynecology, Regional Institute of Medical Sciences, Imphal, Manipur, India ${ }^{2}$ Department of Obstetrics and Gynecology, Lady Hardinge Medical College, New Delhi, India

${ }^{3}$ Department of Biochemistry, Vardhaman Mahavir Medical College and Safdarjung Hospital, New Delhi, India
\end{abstract}

Received: 31 October 2019

Accepted: 03 December 2019

\author{
*Correspondence: \\ Dr. Reena Yadav, \\ E-mail: drreenalhmc@gmail.com
}

Copyright: (c) the author(s), publisher and licensee Medip Academy. This is an open-access article distributed under the terms of the Creative Commons Attribution Non-Commercial License, which permits unrestricted non-commercial use, distribution, and reproduction in any medium, provided the original work is properly cited.

\begin{abstract}
Background: This study was aimed to estimate maternal serum lipid profile and apolipoprotein A levels in pregnancies complicated with FGR and to compare the levels with the levels in normal pregnancies.

Methods: A prospective observational study was conducted in Lady Hardinge Medical College, New Delhi, in a study group consisting of 30 pregnant women at gestation 32-34 weeks with ultrasound diagnosed FGR and control group consisting of 30 age and gestation matched uncomplicated pregnant women. Maternal serum lipid profile and apolipoprotein A levels were measured and compared between the two groups.

Results: Total serum cholesterol, triglyceride, LDL-cholesterol, VLDL-cholesterol and Apolipoprotein A were significantly lower in FGR group compared to normal controls. Mean \pm SD of total cholesterol was found to be $199.17 \pm 49.06 \mathrm{mg} / \mathrm{dl}$ in cases and $244.10 \pm 53.17 \mathrm{mg} / \mathrm{dl}$ in controls. Mean \pm SD of triglyceride was $200.53 \pm 60.25 \mathrm{mg} / \mathrm{dl}$ in cases compared to $304.13 \pm 69.12 \mathrm{mg} / \mathrm{dl}$ in controls. Mean \pm SD of LDL-Cholesterol was $98.19 \pm 37.91 \mathrm{mg} / \mathrm{dl}$ in cases and $127.07 \pm 47.84 \mathrm{mg} / \mathrm{dl}$ in controls. Mean \pm SD of VLDL-cholesterol was $40.11 \pm 12.05 \mathrm{mg} / \mathrm{dl}$ in cases and $60.83 \pm 13.82 \mathrm{mg} / \mathrm{dl}$ in controls. Mean \pm SD of Apolipoprotein A was $147.71 \pm 16.40 \mathrm{mg} / \mathrm{dl}$ in cases compared to $163.30 \pm 16.07 \mathrm{mg} / \mathrm{dl}$ in controls. HDL-cholesterol did not change significantly as its mean \pm SD was $60.87 \pm 15.18$ $\mathrm{mg} / \mathrm{dl}$ in FGR group and $56.20 \pm 16.07 \mathrm{mg} / \mathrm{dl}$ in control group.

Conclusions: The decreased levels of total cholesterol, triglyceride, LDL-cholesterol, VLDL-cholesterol and apolipoprotein A levels may be used as biochemical marker for detection of FGR.
\end{abstract}

Keywords: Apolipoprotein A, Cholesterol, Fetal growth restriction, Triglyceride

\section{INTRODUCTION}

Fetal growth restriction is a condition in which the fetus fails to achieve the inherent growth potential. It is the second most common cause of perinatal morbidity and mortality, following prematurity. ${ }^{1,2}$ The incidence quoted in literatures varies between 3 and $10 \%$ depending upon the population under study and standard growth curve used as references. ${ }^{3}$ It is used to define the fetus whose birth weight is below the $10^{\text {th }}$ percentile or $<2$ SD below the mean weight for that gestational age and or abdominal circumference is less than $10^{\text {th }}$ percentile. $^{4}$

Pregnancy is associated with significant variation in lipid metabolism, consequent mainly to changes to lipoprotein profile. ${ }^{5}$ There is increase in female sex hormones and lipolysis due to placental lactogen which cause an increase in lipid synthesis and lipid metabolism. ${ }^{6}$ The increasing insulin resistance in late gestation and continuously increasing plasma estrogen levels occurring 
during pregnancy are the main hormonal factors responsible for the metabolic changes resulting into the development of maternal hypertriglyceridemia. ${ }^{7}$ The enhanced net breakdown of fat depots during late pregnancy is associated with hyperlipidemia. The physiological basis for this gestational hyperlipidemia is to supply both cholesterol and indirectly triglyceride to the rapidly developing fetus, and to meet the increased maternal energy requirement of late gestation. ${ }^{7}$ The role of lipid metabolism in fetal growth restriction during otherwise normal pregnancy has been recently studied but there is still a shortage of literature in this aspect.

\section{METHODS}

This prospective observational study was conducted at Lady Hardinge Medical College, New Delhi, on 30 pregnant women with FGR who satisfy the inclusion criteria (study group) and 30 appropriately matched women for maternal age and gestational period with normal pregnancy (control group), from December 2013 to March 2015. Inclusion criteria included singleton pregnancies at gestational age 32-34 weeks with ultrasound diagnosed FGR (AC $<10^{\text {th }}$ percentile). Hypertensive disorders of pregnancy, maternal obesity, maternal diabetes, maternal alcohol consumption, antenatally detected fetal congenital anomaly or malformations, known cases of maternal hepatic/renal/thyroid disease and multifetal pregnancy were excluded. After explaining to the patient, informed consent was taken. Height, weight and BMI were measured. Blood samples were obtained by venepuncture in sitting position after at least 10 hours fasting. Serum lipid profile was estimated by enzymatic method and Apolipoprotein A were measured by turbidimetric method. After delivery, a detailed examination of the baby including anthropometry was done. FGR in this study was defined as birth weight $<10^{\text {th }}$ percentile for gestational age as determined by Lubchenco's charts. Results were analyzed using standard statistical methods.

\section{RESULTS}

Table 1 shows that there was no statistically significant difference between the mean Body Mass Indexes of the study and control groups. Mean \pm SD of Amniotic Fluid Indexes of the study and control group was $7.44 \pm 3.65 \mathrm{~cm}$ and $12.72 \pm 2.30 \mathrm{~cm}$ respectively whose difference was statistically significant. The mean $\pm \mathrm{SD}$ of gestational age of study group at birth was $36.1 \pm 1.3$ weeks whereas that of control group was $39.3 \pm 1.4$ weeks. The difference was statistically significant. The mean $\pm \mathrm{SD}$ of birth weights of the babies in the study and control groups were $1.88 \pm 0.54$ $\mathrm{kg}$ and $2.90 \pm 0.89 \mathrm{~kg}$ respectively whose difference again was statistically significant.

Table 2 shows that total cholesterol, triglyceride, LDLcholesterol, VLDL-cholesterol and apolipoprotein A were found to be significantly decreased in FGR group as compared to control group. HDL-cholesterol was found to be increased in FGR group but the difference was not statistically significant.

Table 1: Comparison of clinical variables between study group and control group.

\begin{tabular}{|llll|}
\hline Clinical variables & Study group & Control group & p-value \\
\hline Maternal age (years) & $25.53 \pm 4.88$ & $25.53 \pm 4.88$ & 1.00 \\
\hline BMI $\left(\mathrm{kg} / \mathrm{m}^{2}\right)$ & $22.72 \pm 1.97$ & $23.13 \pm 1.60$ & 0.380 \\
\hline Amniotic fluid index (cm) & $7.44 \pm 3.65$ & $12.72 \pm 2.30$ & $<0.001$ \\
\hline Gestational age at birth (weeks) & $36.1 \pm 1.3$ & $39.3 \pm 1.4$ & $<0.001$ \\
\hline Birth weight $(\mathrm{kg})$ & $1.88 \pm 0.54$ & $2.90 \pm 0.89$ & $<0.001$ \\
\hline
\end{tabular}

Table 2: Comparison of lipid parameters and apolipoprotein A between study group and control group.

\begin{tabular}{|llll|}
\hline Lipid parameters/apolipoprotein A concentration $(\mathbf{m g} / \mathbf{d l})$ & Study group & Control group & p-value \\
\hline Total cholesterol & $199.17 \pm 49.06$ & $244.10 \pm 53.17$ & 0.001 \\
\hline Triglyceride & $200.53 \pm 60.25$ & $304.13 \pm 69.12$ & $<0.001$ \\
\hline HDL & $60.87 \pm 15.18$ & $56.20 \pm 10.79$ & 0.175 \\
\hline LDL & $98.19 \pm 37.91$ & $127.07 \pm 47.84$ & 0.018 \\
\hline VLDL & $40.11 \pm 12.05$ & $60.83 \pm 13.82$ & $<0.001$ \\
\hline Apolipoprotein A & $147.71 \pm 16.40$ & $163.30 \pm 17.07$ & $<0.001$ \\
\hline
\end{tabular}

\section{DISCUSSION}

It is well known that normal fetal development needs the availability of both essential fatty acids and long chain polyunsaturated fatty acids, thus making a persuasive case indicating a relationship between nutritional status of mother during gestation reflecting her lipid profile and fetal growth. ${ }^{8}$ In the recent past, several studies have been conducted to find out the correlation between maternal serum lipid profile and Apolipoproteins and fetal growth. In a study, more or less consistent with the present study, Dabi DR et al, observed serum total cholesterol, 
triglycerides, LDL-cholesterol and VLDL-cholesterol to increase with increasing gestational age (at sampling) in normal pregnancies while all these decreased with increasing gestational age (at sampling) in pregnancies with fetal growth retardation. ${ }^{5}$ HDL-cholesterol decreased with increasing gestational age (at sampling) in normal pregnancies while it increased in pregnancies complicated with FGR. But there was no statistically significant correlation between increasing gestational age and HDL cholesterol values in both the groups. Serum total cholesterol and LDL- cholesterol of the study group (203.2 $\pm 28.95 \mathrm{mg} / \mathrm{dl} ; 127.25 \pm 25.11 \mathrm{mg} / \mathrm{dl}$ respectively) were significantly lower ( $\mathrm{p}<0.001)$ as compared to those of the control group $(249.94 \pm 24.58 \mathrm{mg} / \mathrm{dl} ; 175.04 \pm 24.46$ $\mathrm{mg} / \mathrm{dl}$ respectively). However, there was no statistically significant difference between the serum triglycerides, HDL and VLDL cholesterol values of the two groups.

Miranda $\mathrm{J}$ et al, in their prospective study, a cohort of singleton gestation with antenatal suspicion of fetal smallness and diagnosis established later than 32 weeks of gestation were taken as cases $(n=52) .{ }^{9}$ A control group of 28 pregnancies with appropriate for gestational age fetuses were selected among low risk pregnancies in third trimester. Maternal blood samples were drawn 2-4 hours after delivery and analyzed. Lipoprotein profiles showed significantly lower plasma concentrations of cholesterol-intermediate density lipoprotein (IDL), triglyceride -IDL and HDL in mothers with FGR compared to controls ( $p<0.05$ ). They highlighted that findings of their study and previous studies suggest (1) failure of the normal signaling leading to increased lipids in pregnancy, and/or (2) a reduction in lipid reserve in the mothers.

In a similar study conducted by Sattar et al, they observed comparable median triglyceride, VLDL1, and HDL concentrations in FGR and controls. They also found that median cholesterol and LDL-cholesterol concentrations were significantly lower in FGR cases $(p<0.01) .{ }^{10}$ In addition, median total VLDL2, IDL, and LDL concentrations were also significantly lower in women with FGR ( $\mathrm{p}<0.01)$.

Munoz et al in their study observed that plasma triglyceride, LDL-cholesterol and total cholesterol increase progressively throughout pregnancy with significantly higher values after $25^{\text {th }}$ week of gestation. ${ }^{6}$ They found that triglyceride concentration were significantly lower in the FGR group than in the normal group. There was no difference in other lipids.

In the study conducted by Bae JG et al, they observed that total cholesterol $(6.74 \pm 1.14 \mathrm{mmol} / \mathrm{L}$ versus $4.23 \pm 1.03 \mathrm{mmol} / \mathrm{L}, \quad \mathrm{p}<0.01)$, triglyceride $(2.10 \pm 0.95$ $\mathrm{mmol} / \mathrm{L}$ versus $2.42 \pm 0.73 \mathrm{mmol} / \mathrm{L}, \mathrm{p}<0.05)$, and $\mathrm{LDL}$ $(3.41 \pm 0.83 \mathrm{mmol} / \mathrm{L}$ versus $4.23 \pm 1.07 \mathrm{mmol} / \mathrm{L}, \mathrm{p}<0.01)$ concentrations were significantly lower in FGR group than in control group. ${ }^{11}$ There were no differences in other lipids. They concluded that LDL which normally increase in uncomplicated pregnancies, fail to rise appropriately in pregnancies complicated by FGR and may play a role in pathogenesis of fetal growth restriction.

In a more or less similar study conducted by Contini $\mathrm{C}$ et al, they found low cholesterol levels in FGR group as compared to control group $(\mathrm{p}=0.0405) .{ }^{12}$ They concluded that low cholesterol especially LDL cholesterol levels are feature of FGR.

Borna $S$ studied to determine relationship between maternal lipid profile and amniotic fluid lipid profile in the second trimester with pregnancy outcome. ${ }^{13} 142$ pregnant women with gestational age between 16 and 22 weeks were enrolled, $2 \mathrm{ml}$ of amniotic fluid was taken by amniocentesis, venous samples of fasting mothers were collected for lipid profile analysis. He found that mean maternal serum cholesterol, triglyceride and amniotic fluid cholesterol and triglyceride were significantly different between term and preterm, FGR and non FGR and low birth weight and normal weight neonates. He also concluded that maternal and amniotic fluid lipid profiles could be good indicators for fetal growth.

But, in a contradictory way, the study conducted by Rodie $\mathrm{VA}$ et al, showed no significant differences in the mean concentrations $(\mathrm{mmol} / \mathrm{L})$ of total cholesterol $(6.32 \pm 1.07$, and $5.79 \pm 0.77, \quad \mathrm{p}=0.11) ; \quad \log$ triglyceride $(0.42 \pm 0.17$ and $0.40 \pm 0.14, \mathrm{p}=0.67)$; VLDL $(0.77 \pm 0.46$ and $0.71 \pm 0.21$, $\mathrm{p}=0.62)$; LDL (3.9 \pm 1.05 and $3.54 \pm 0.82, \mathrm{p}=0.28)$ and $\log$ HDL cholesterol $(0.21 \pm 0.09$ and $0.19 \pm 0.08, \quad \mathrm{p}=0.37)$ between FGR group and their control respectively. ${ }^{7}$

Tanja GMV et al, also conducted a study to investigate whether nonfasting total cholesterol and triglyceride levels during early pregnancy are associated with six major adverse pregnancy outcomes i.e. pregnancy induced hypertension $(\mathrm{PIH})$, preeclampsia, preterm birth, small/large for gestational age (SGA/LGA), and child loss. ${ }^{14}$ Random blood samples of non-fasting total cholesterol and triglyceride levels were determined during early pregnancy $($ mean $=13$, interquartile range $=$ 12-14 weeks). After adjustments, they found that every unit increase in triglyceride levels was linearly associated with an increased risk of PIH $(\mathrm{OR}=1.60, \mathrm{p}=0.021)$, preeclampsia $(\mathrm{OR}=1.69, \mathrm{p}=0.018), \mathrm{LGA}(\mathrm{OR}=1.48, \mathrm{p}$ $=0.001)$ and induced preterm delivery $(\mathrm{OR}=1.69, \mathrm{p}=$ 0.006). They found no associations for SGA and child loss. Total cholesterol was not associated with any of the outcome measures.

In the present study also, as mentioned in the study by Dabi DR et al, it is possible that the decreased concentration of serum total cholesterol, serum triglyceride, VLDL and LDL cholesterol may have decreased the availability of glycerol, long chain polyunsaturated fatty acids and essential fatty acids to the fetuses of mothers with otherwise normal pregnancy ultimately leading to fetal growth restriction. ${ }^{5}$ Besides, like Munoz et al, it is also not clear regarding the exact 
reason for such low lipid levels in FGR pregnancies observed in this study. ${ }^{8}$

As stated by Sattar et al, in their study, the exact mechanism for lower cholesterol in FGR is not known. ${ }^{10}$ Neither we have any information regarding booking first trimester lipid levels. So, it also cannot rule out the possibility of women destined to develop FGR have low starting cholesterol values or there may be failure of appropriate rise of lipid levels in pregnancies complicated by FGR.

In this study, apolipoprotein A level was found to be significantly lower in FGR group than in control group. Likewise, in the study by Munoz A et al, they observed that apolipoprotein A levels were significantly lower in the FGR group $(2.60 \pm 0.42 \mathrm{~g} / \mathrm{l}, \mathrm{p}<0.05)$ than in the normal group $(2.25 \pm 0.55 \mathrm{~g} / \mathrm{l}, \mathrm{p}<0.05){ }^{6}$ The HDL/Apo A ratio in their study was also higher in the FGR group than in the control group.

\section{CONCLUSION}

This study shows, to some extent, the relationship between maternal lipid and apolipoprotein A levels with fetal growth restriction. It can be put forward as an implication that failure of maternal serum lipids especially total cholesterol, triglyceride, LDL-cholesterol, VLDL-cholesterol, and apolipoprotein A levels to rise appropriately compromises the supply of substrate for energy production resulting in FGR. These lipid parameters may be used as biomarkers for detection of, or at risk of developing FGR. But, to confirm this finding, it is recommended that more longitudinal studies in a larger population need to be done analyzing maternal serum lipid profile along with apolipoprotein $\mathrm{A}$ in uncomplicated FGR pregnancies.

Funding: No funding sources

Conflict of interest: None declared

Ethical approval: The study was approved by the Institutional Ethics Committee

\section{REFERENCES}

1. Bernstein I, Gabbe SG. Intrauterine growth restriction. In: Gabbe SG, Niebyl JR, Simpson JL, Annas GJ, et al (Eds). Obstetrics: Normal and Problem Pregnancies. New York: Churchill Livingstone; 1996;3:863-86.

2. Wolf HM, Gross TL. Increased risk to the growth retarded fetus. In: Gross TL, Sokol RJ, (Eds). Intauterine Growth Retardation: a practical approach. Chicago: Year Book Medical Publishers; 1989: 111124.
3. Creasy RK, Resnik R. Intrauterine growth restriction. In: Creasy RK, Resnik R (Eds). Maternal Fetal Medicine: Principles and Practice. Philadelphia: Saunders. 1994;3:558-74.

4. Battaglia FC, Lubchenco LO. A practical classification of newborn infants by weight and gestational age. J Pediatr. 1967;71:159-63.

5. Dabi DR, Parakh M, Goyal V. A cross sectional study of lipids and lipoproteins in pregnancies with intrauterine growth retardation. J Obstet Gynecol. 2004;54(5):467-72.

6. Munoz A, Uberos J, Molina A, Valenzuela A, Cano D, Cruiz C, et al. Relationship of blood rheology to lipoprotein profile during normal pregnancies and those with intrauterine growth restriction. J Clin Pathol. 1995;48:571-4.

7. Rodie VA, Caslake MJ, Stewart F, Sattar N, Ramsay JE, Greer IA, et al. Fetal cord plasma lipoprotein status in uncomplicated human pregnancies and pregnancies complicated by pre-eclampsia and intrauterine growth restriction. Atheroscl. 2004;176:181-7.

8. Herrera E. Lipid metabolism in pregnancy and its consequences in the foetus and newborn. Endocrine. 2000;19:43-55.

9. Miranda J, Simoes RV, Pauls C. Metabolic profiling and targeted lipidomics reveals a disturbed lipid profile in mothers and foetuses with intrauterine growth restriction. Scientific Reports. 2018;8:13614.

10. Sattar N, Ian AG, Peter JG, Chris JP, James S, Theresa K, et al. Lipid and Lipoprotein concentrations in pregnancies complicated by intrauterine growth restriction. J Clin Endocrinol Metabol. 1999;84(1):128-30.

11. Bea JG, Park JC. Rhee JH, Kim JI. Comparison of plasma lipids and lipoprotein concentrations in normal and intrauterine growth restriction pregnancies. Korean J Obstet Gynecol. 2009;52(4):400-6.

12. Contini C, Winkler BS, Maass N, Alkatout I, Winkler K, Pecks U. Concomitant intrauterine growth restriction alters the lipoprotein profile in preelampsia. Preg Hyper. 2019;15:154-60.

13. Borna S. Relationship between amniotic fluid and maternal lipid profiles for predicting pregnancy outcome. Ultrasound Obstet Gynecol. 2016;48(1):336.

14. Tana GMV, Nathalie K, Barbara A. Maternal lipid profile during early pregnancy and pregnancy complications and outcomes: the ABCD Study. J Clin Endocrinol Metab. 2012;97(11):3917-25.

Cite this article as: Devi AT, Yadav R, Yadav A, Singh YA. Study of maternal serum lipid profile and apolipoprotein a levels and its correlation with fetal growth restriction. Int J Reprod Contracept Obstet Gynecol 2020;9:270-3. 